\title{
CUANDO LA DIVERSIDAD CULTURAL LLEVA FONENDO. LOS «NUEVOS MÉDICOS» EN LA ATENCIÓN PRIMARIA DE LES TERRES DE L'EBRE
}

LOURDES FRANCO LóPEZ Máster Interuniversitari en Antropologia Mèdica i Salut Clobal, MARC lourdesfl76@gmail.com

RESUMEN: Las migraciones forman parte de la historia de la humanidad, trasformando las sociedades en poliétnicas. Nos centraremos en el perfil de trabajadores altamente cualificados, concretamente médicos.

Actualmente la situación laboral en el sistema sanitario público catalán es compleja; la falta de personal facultativo para cubrir las necesidades existentes y futuras ofrecerá oportunidades para la incorporación de médicos extranjeros, introduciendo una diversidad cultural que podría generar cambios en el funcionamiento de la institución. El objetivo principal es analizar los discursos y las prácticas que se generan en torno a estos procesos de incorporación en la atención primaria del sistema sanitario público en les Terres de l'Ebre. Especificar los factores que producen esta introducción, conocer las relaciones que se establecen con el resto de médicos autóctonos y las experiencias sentidas por las personas atendidas por estos profesionales.

El porcentaje de médicos de familia extranjeros en el territorio estudiado es de $15,85 \%$, siendo el perfil mayoritario mujeres jóvenes latinoamericanas con contratos eventuales. Se produce un efecto de etiquetaje social y de categorización jerárquica según el origen y el tipo de formación. El contexto laboral genera una atracción para este tipo de migración y una adaptación al fenómeno por parte de todos los actores implicados. 
PALABRAS CLAVE: migración cualificada; sanidad pública; médicos extranjeros; relación médico-paciente.

ABSTRACT: Migrations are part of humanity's history, transforming societies into polyethnic entities. We will focus on highly qualified workers, specifically physicians,

The current employment situation in the Catalan public health system is complex; the lack of trained staff to meet existing and future needs will offer opportunities for foreign doctors, thus introducing a cultural diversity that could generate changes in the functioning of the institution. The main objectives are to analyse the discourses and practices that are generated around the processes of employing foreign doctors in the primary healthcare system in les Terres de l'Ebre region, to specify the factors that have led to their introduction, and to determine the relationships that are established with the native doctors and the experiences felt by the people attended by these professionals.

The percentage of foreign family physicians in the territory studied is $15.85 \%$, most of whom are young Latin American women with temporary contracts. This produces a social labelling effect and a hierarchical categorization based on origin and type of training. The working context attracts these types of migrants and leads to adaptation by by all the actors involved.

KEYWORDS: qualified migration; public health; foreign physicians; doctor-patient relationship. 


\section{Introducción}

«Las migraciones internacionales son procesos condicionados, sujetos a pautas y limitaciones» (Sassen, 2013:28), que pueden considerarse como un puente entre dos mundos. Así, en las últimas décadas, Cataluña se ha trasformado en multicultural, multilingüe y multirreligiosa, con los consecuentes efectos sociales, políticos y económicos.

Los procesos migratorios son complejos y globales, existiendo diferentes formas y perfiles de migración. En este artículo nos centraremos en el perfil de los trabajadores altamente cualificados, más concretamente en los licenciados y especialistas médicos.

Hay que diferenciar entre política de inmigración y política de inmigrados ejercidas por el Estado nación. La primera se «refiere a la regulación de los flujos migratorios y al control de los extranjeros y de las fronteras» (Martiniello, 2003: 33). La segunda «comprende el conjunto de disposiciones legales y de las prácticas administrativas que regulan la vida del inmigrado en su nuevo país» (Martiniello, 2003: 33). De esta forma, se regula la transformación de los inmigrantes en ciudadanos. Así, siguiendo a Hage (2000; 2003), el grado de pertenencia social que la sociedad de acogida brinda a los individuos inmigrantes está estrechamente relacionado con la ciudadanía como derecho, la integración laboral, la calidad de la misma y la proximidad cultural, la cual, si es alta, puede asemejarse a la cultura autóctona, creando un mayor capital nacional, que, juntamente con lo que Bourdieu (2002) denomina campo de poder, determina el grado de inclusión o exclusión que el inmigrante asumirá (Garzón, 1996). Se trata, pues, de observar el melting pot, entendido en «términos de pluri-etnicidad, esto es, de la interacción de diferentes grupos sociales dotados de valores, sistemas de comportamiento y de visiones del mundo contrastadas» (Pujadas, 1993:35), así como los procesos de integración, siendo este un «proceso de gran complejidad (entendido) en términos de acción colectiva, englobando como actores los "viejos nacionales" y 1os "recién llegados", que negocian su copresencia en el espacio público» (Bastenier y Dassetto, 1993, citado en Herrera 1994: 6).

Por otro lado, «la interacción social se fundamenta, tanto en la concepción que el sujeto social tiene de uno mismo ("oneself"), como de la imagen 
que se tiene de los otros con los que interactúa, así como de la propia objetivación ("self objetification")» (Pujadas, 1993: 57). Los individuos somos capaces de reconocer, identificarnos y decodificar la simbología, las actitudes y la conducta de los otros, siempre que tengamos un conocimiento previo de ellas, lo cual se logra mediante clasificaciones estereotipadas que se denominan etiquetas sociales. «El etiquetaje social hay que entenderlo como una dialéctica constante en que los propios criterios clasificatorios y autoclasificatorios del continuum de diferencias sociales está en constante redefinición» (Pujadas, 1993: 63). Según el autor, el etiquetaje restringiría la libertad de opción de los individuos, precondicionando sus interacciones, lo cual puede generar rechazo por formas o aspectos del bagaje cultural de los inmigrantes, lo que reforzará la conciencia de diferenciación étnico-cultural; o bien, basado en sus características fenotípicas, lo que incidirá en el refuerzo de su identidad racial.

La migración de los trabajadores sanitarios se distingue porque está fuertemente influenciada por los marcos reguladores de los diferentes Gobiernos que controlan la formación, la contratación y el despliegue de profesionales de la salud. Además, el trabajo en el sector de la salud se caracteriza tanto por un proceso de mano de obra altamente cualificado, interdependiente, como por la proliferación de roles profesionales especializados con largos períodos formativos. Así pues, las motivaciones para realizar la migración son el deseo de mayores ingresos, un mejor acceso a la tecnología, un entorno de estabilidad y seguridad, un nivel insuficiente de satisfacción laboral y unas mejores perspectivas para sus hijos.

En Europa hace décadas que las migraciones de profesionales sanitarios vienen sucediendo. Países como el Reino Unido (RU) están considerados como de "gran escala» para la migración de facultativos, y este se encuentra entre los cuatro países del mundo, junto con Australia, Canadá y Estados Unidos (EE. UU.), que cuentan con un porcentaje mayor al 20\% de médicos extranjeros. Eastwood et alii (2005) han categorizado estos movimientos migratorios a gran escala como un carrusel médico, iniciándose en países pobres, donde los médicos buscan oportunidades educativas, condiciones de trabajo más favorables y salarios más altos en países con mayor renta per cápita. Podemos observar que se trata de un 
fenómeno social complejo en el que intervienen numerosas cuestiones relacionadas con situaciones laborales, demográficas, políticas públicas, etc.

En España, «no hemos sido capaces de abordar con éxito los desajustes entre la oferta y la demanda [...]. [Como] tampoco se ha evaluado la capacidad del sistema para dotar puestos de trabajo en número y ritmo» (Martínez, Guiu e Ibáñez, 2008: 134). Actualmente se corre el riesgo de un déficit en la cobertura de facultativos, sobre todo en la atención primaria (AP), debido a razones demográficas y de condiciones de trabajo, las cuales eran previsibles y que a continuación se exponen de forma sintética.

Se presenta la situación en Tarragona, ya que existe una falta de datos oficiales sobre el tema que nos ocupa. En primer lugar, tenemos una población médica envejecida. Según publica la revista Galens, está prevista la jubilación de 669 médicos que trabajan en AP hasta 2025 (Col.legi Oficial de Metges de Tarragona, 2016:15).

En segundo lugar, existe una gran precarización laboral en el sector. Durante los años 2014 y 2015, la Organización Médica Colegial (OMC) realizó, a través de los Colegios Oficiales de Médicos provinciales, una encuesta online a todos los colegiados. En total se recogieron datos de 32.000 facultativos de todo el territorio español, en tres momentos temporales diferentes y consecutivos. Los resultados de esta encuesta son alarmantes y convierten al Sistema Nacional de Salud en la mayor empresa de trabajo temporal en España. El 50\% de los médicos que actualmente trabajan sin plaza en propiedad, es decir, que no han ganado un concurso de oposición, lo hacen con un contrato en situación de irregularidad o inestabilidad (OMC, 2016). En les Terres de l'Ebre, según los informantes y compañeros facultativos, no existe paro entre el colectivo. Todos los médicos apuntados en la bolsa de trabajo están trabajando en estos momentos, aunque no se especifican la calidad de los contratos ni las condiciones del trabajo. Los recortes que los diferentes Gobiernos han realizado amparados por la crisis económica también han creado situaciones de precariedad laboral. En Galens, otro artículo publica que «en la AP han aumentado exponencialmente las visitas y se ha dado respuesta con menos recursos» (Col-legi Oficial de Metges de Tarragona, 2016: 12), 
de esta forma, en los últimos cinco años se han perdido 92 médicos en los centros de AP del Institut Català de la Salut (ICS) en la demarcación de Tarragona (Collegi Oficial de Metges de Tarragona, 2016). Todo ello tiene una repercusión directa en la salud de la población atendida, ya que conlleva un aumento en las listas de espera y, por tanto, una dificultad de acceso al médico habitual, lo que comporta una desviación de la demanda hacia los servicios de atención continuada y urgencias, la saturación de las consultas y una carga de trabajo extra para los profesionales que acusan el cansancio, aumentando la probabilidad de error.

En tercer lugar, en la provincia de Tarragona, en 2015, se solicitaron 51 certificados de idoneidad profesional para acceder a trabajos en otros países, incrementándose un 29,5\% desde 2012 . Las causas de esta demanda se atribuyen a la «desconfianza y la incerteza sobre su futuro profesional en el país» (Col-legi Oficial de Metges de Tarragona, 2016:13), así como a las dificultades existentes para establecer perspectivas de estabilidad familiar y reproductiva.

La situación planteada para la provincia de Tarragona puede ser extrapolable para el resto del territorio español, según podemos observar a través de las redes sociales, siguiendo a diversos profesionales de la atención primaria, como Juan Gérvas, Mónica Lalanda, Salvador Casado y Rafael Bravo, entre otros muchos, que critican y denuncian las condiciones laborales y los abusos del sistema sanitario hacia los facultativos.

Además, el número de médicos a formar y su distribución por especialidades es una decisión política que tiene repercusiones a largo plazo. El Grado de Medicina es uno de los más demandados por los estudiantes, lo que provoca que las notas de corte para entrar en la facultad sean elevadas (Redacción Médica, 2016). «La duración media de los estudios [de Medicina] es de 6,3 años. La evolución de matriculados y licenciados en las facultades de medicina españolas tiende a estabilizarse en torno a 4.0005.000 nuevos licenciados cada año tras la implantación de los numerus clausus» (Martínez, Guiu, Ibánez, 2008:133).

He enumerado algunas de las razones que generan situaciones de inestabilidad para los profesionales autóctonos, aunque es posible que existan otras causas de carácter local, ligadas a las particularidades de los 
diferentes territorios. En conjunto, producen un espacio de oportunidad para la entrada en el mercado laboral de profesionales de orígenes diversos. Pero estas mismas situaciones pueden crear prejuicios, estigmas y competitividad entre los locales con respecto a los extranjeros.

El Sistema Sanitario Integral de utilización pública de Cataluña del Departamento de Salud (SISCAT) concierta la actividad pública con las diferentes empresas proveedoras de servicios de salud. La principal empresa suministradora de servicios de salud es el ICS, que es de titularidad pública y está presente en la mayoría del territorio catalán. Pero también existen numerosos consorcios y entidades de titularidad privada (algunos con gestión pública) que suministran servicios de salud de forma local, los cuales se agrupan en la Red Hospitalaria de Utilización Pública (XHUP).

El territorio de estudio se enmarca en la zona meridional de Cataluña (España), en la región conocida como les Terres de l'Ebre y compuesta por cuatro comarcas: el Baix Ebre, el Montsià, la Terra Alta y la Ribera d'Ebre. En este territorio, la red pública de salud cuenta con un hospital de referencia en Tortosa que gestiona el ICS y dos más de titularidad municipal y pertenecientes a la XHUP, en Mora d'Ebre y en Amposta, los cuales ofrecen tanto servicios privados como asistencia pública. La red de atención primaria (AP) está gestionada en su totalidad por el ICS (que es la empresa pública de provisión de servicios sanitarios en Cataluña), compuesta por 11 equipos de atención primaria (EAP) (conjunto de profesionales que atienden a la población habitante de un área básica de salud, $\mathrm{ABS}$ ) que dan servicio a la población en los centros de atención primaria (CAP), donde se comparte el espacio por varios médicos, y consultorios locales, donde los médicos trabajan solos. En conjunto, y según los datos del padrón continuo a fecha de 1 de enero de 2016, se atendía a una población total de 182.867 habitantes repartidos entre 52 municipios, en cada uno de los cuales hay, como mínimo, un consultorio médico. En este estudio me centro únicamente en la red pública de AP, ya que el estudio se enmarca en un trabajo final de máster y lo que me interesaba era describir esta situación en particular, ya que las entidades públicas proveedoras de salud (en este caso, el ICS) están sujetas a la Directiva 93/16/CEE 
del Consejo, de 5 de abril de 1993, en la que obliga a tener la condición de especialista vía MIR para ser contratado. Cosa que se incumple en ocasiones, sobre todo con médicos extranjeros.

El MIR (médico interno residente) es un período formativo posgrado, de entre cuatro a cinco años, al que se accede mediante un duro examen de conocimientos generales sobre medicina, para el cual los licenciados suelen prepararse un mínimo de un año. Se trata de una formación activa, es decir, durante la actividad laboral, siendo el MIR supervisado por otros especialistas tutores, quienes son los encargados de que el residente adquiera los conocimientos necesarios para el correcto desarrollo de la especialidad seleccionada. Esta es la vía elegida en nuestro país para garantizar la formación adecuada de los diferentes facultativos especialistas y un nivel asistencial y de seguridad clínica idónea.

\section{Objetivos de la investigación}

Según hemos visto, se plantea una situación laboral en el sistema sanitario público catalán, y por extensión en el español, bastante compleja; en la cual la falta de personal facultativo para cubrir todos los espacios posibles que existen en la actualidad y los que se prevé que surgirán en un futuro inmediato ofrecerá oportunidades para la incorporación de médicos extranjeros en un número elevado, introduciendo una diversidad cultural dentro del sistema sanitario que podría generar cambios en el funcionamiento de la institución.

Para explorar esta situación, el presente trabajo tiene como objetivo principal analizar los discursos y las prácticas que se han ido generando en torno a los procesos de incorporación de los profesionales facultativos provenientes de otros países en la AP del sistema sanitario público catalán, y en particular en les Terres de l'Ebre. Así como conocer las relaciones que se generan con los diferentes actores en el espacio laboral, además de considerar las experiencias que comporta la migración y concluyen con la estabilización laboral en destino. También, especificar los factores político-sociales que generan la incorporación de la multiculturalidad en el colectivo médico del territorio estudiado y conocer las relaciones que se establecen con el resto de médicos autóctonos, tanto desde el punto de 
vista personal como desde el profesional y las experiencias sentidas por las personas atendidas por estos profesionales, respecto a la elaboración de la relación médico-paciente, y a la eficiencia y resolución de los problemas planteados a los mismos.

Dada la ausencia de datos estadísticos respecto a la presencia de médicos extranjeros en la zona de estudio, planteo describir y caracterizar la demografía médica de les Terres de l'Ebre.

\section{Hipótesis}

La situación demográfica del colectivo médico, juntamente con unas condiciones laborales precarias, fruto de la crisis económica y la mala gestión del sistema, producen un efecto llamada para médicos extranjeros, otorgando espacios para su introducción en el sistema sanitario. Esta incorporación mantiene patrones similares a los de otros países vecinos aunque de una forma más acelerada.

La aceptación por parte de la población de médicos extranjeros está relacionada con el propio facultativo independientemente de su origen, así como con estigmas y prejuicios relacionados con los etiquetajes sociales. En cambio, la aprobación por parte de los iguales estaría más relacionada con cuestiones formativas, de eficiencia y resolutividad, así como, también, con los prejuicios ligados a su origen. Además, estaría actuando una discriminación institucional que mantiene a estos profesionales en situaciones de precariedad y vulnerabilidad laboral, cosa que genera mayor inestabilidad, aumentando la movilidad y produciendo estigmatización, lo que limita sus posibilidades de mejora laboral.

\section{Diseño del estudio}

Utilicé técnicas de análisis con metodología mixta: cuantitativa para analizar los datos obtenidos de la demografía médica, y cualitativa de base etnográfica para el conocimiento de los discursos y las prácticas de los actores implicados.

El ámbito de estudio se localiza, como hemos descrito anteriormente, en les Terres de l'Ebre. Se trata de una zona mayoritariamente rural que 
engloba los territorios regados y dependientes al final del recorrido del río Ebro; a pesar de ello existe algún núcleo urbano, los más relevantes, con más de 20.000 habitantes, son Tortosa (ciudad de referencia para todo el territorio) y Amposta. Mi presencia en territorio como médico de familia que trabaja en la AP me confiere una experiencia previa y facilita el desarrollo de la investigación.

Por tanto, la población de estudio fueron todas aquellas personas que vivían en esta región y que cumplían los criterios de inclusión: a) licenciados en Medicina con nacionalidad extranjera, $b$ ) médicos nacidos en territorio español, y c) usuarios de los servicios de salud de atención primaria. Incluí todos aquellos individuos que, siendo mayores de edad y cumpliendo criterios de inclusión, aceptaron la propuesta de participar en el estudio.

Realicé entrevistas individuales en los tres perfiles de informantes. Creí conveniente utilizar esta técnica, para crear un clima de intimidad, teniendo en cuenta mi proximidad con la mayor parte de los entrevistados, que les permitiese opinar abiertamente y sin coacciones por la presencia de otros iguales. Las entrevistas fueron en profundidad, estandarizadas, no programadas, basadas en un guion pero con un enfoque no directivo, semiestructuradas y abiertas en la medida de lo posible y según la predisposición del informante, orientadas a obtener los datos necesarios para el objetivo del estudio. Distinguí tres perfiles de informantes: 1) médicos extranjeros, para los que me interesó conocer sus trayectorias migratorias, el proceso de introducción al mercado laboral como profesionales sanitarios y sus experiencias con los demás actores relacionadas con su origen; 2) médicos autóctonos, con los que se comentaron sus opiniones y experiencias con los compañeros extranjeros, y 3) usuarios, como población potencialmente atendida por los médicos extranjeros. Quería saber las opiniones acerca de su presencia en la sanidad pública y el grado de aceptación. Por otro lado, para conocer los discursos institucionales, realicé entrevistas a una de las coordinadoras territoriales, la cual es la encargada de las contrataciones; al concejal de Salud del Ayuntamiento de Alcanar, como representante político para aportar el punto de vista oficial de la población, ya que recoge las quejas y malestares de 
los ciudadanos, y a los representantes de los sindicatos mayoritarios del estamento médico de la zona, para recoger la situación laboral del colectivo, las posibles reivindicaciones y los discursos generales respecto a la presencia de médicos extranjeros en el territorio.

Para analizar los resultados utilicé como soporte en el análisis de los datos cuantitativos el programa informático SPSS, realizando un análisis descriptivo y bivariante, utilizando la prueba de $\chi^{2}$ para las variables dicotómicas y $t$ de Student para las variables continúas. Para el análisis de los datos cualitativos, transcribí las entrevistas para su posterior análisis, observando similitudes en las unidades de análisis que permitían su comparación. La codificación de la información la diferencié según la información hubiese sido aportada por los usuarios, por los médicos extranjeros o por los médicos autóctonos. Los datos recogidos de cada grupo los organicé según los siguientes ámbitos de clasificación:

- Representaciones culturales y sociales de la figura del médico.

- Descripción de los discursos hacia los profesionales extranjeros, por parte de los usuarios y de los médicos autóctonos.

- Percepciones relacionales de los diferentes actores hacia las otras dos categorías.

- Comparación intercultural de las prácticas clínicas de ambos perfiles sanitarios.

- Diferenciación de la práctica clínica originada por la migración.

- Problemáticas percibidas por los grupos.

Las entrevistas institucionales las analicé independientemente, codificando las probables causas de la demanda de médicos extranjeros, así como los discursos alrededor de su incorporación al sistema sanitario.

La participación de todos los entrevistados se sometió a las normas éticas que rigen los estudios cualitativos. Obteniendo los consentimientos informados de su participación, previa información del estudio, siendo su colaboración totalmente voluntaria y pudiendo ejercer su derecho de retirarse del estudio en cualquier momento. Los informantes no obtuvieron ninguna compensación económica por su participación en la investigación. 


\section{Resultados}

\subsection{Análisis cuantitativo}

\subsubsection{Tarragona}

Analizando los datos sobre demografía médica proporcionados por el COMT para la provincia de Tarragona, encontré que hay 3.238 médicos colegiados en la provincia, con una media de edad de 49,33 [DT $\pm 14,287$ ], un $25 \%$ de los cuales están por encima de los 59 años. El 51,2\% (1.657) son mujeres y el 15,2\% (492) tienen nacionalidad diferente a la española, con hasta 49 nacionalidades, que si se agrupan por zonas geográficas se observa que 385 provienen de países latinoamericanos, 53 de países del este (incluyendo a Rumanía, Rusia y los países de la antigua Unión Soviética), 27 del resto de países europeos, 11 son de origen magrebí y otros 10 de Oriente Medio, 2 asiáticos y 4 norteamericanos.

\subsubsection{Terres de l'Ebre}

Según los datos aportados por la SAP de les Terres de l'Ebre, trabajan en AP 178 médicos, 164 especialistas en medicina familiar y comunitaria, 13 pediatras y un especialista en cirugía ortopédica y traumatología. 102 son mujeres, un $57,3 \%$, con una edad media de 50,84 años [DT $\pm 10,147]$, estando el 28,1\% por encima de los 60 años. El tipo de contratación se divide en contratos indefinidos (interinos y definitivas por oposición), con el $88,2 \%$ de los facultativos en esta situación, y, por otro lado, los contratos temporales (refuerzos, eventuales, sustituciones), en esta categoría encontramos al $11,8 \%$.

En cuanto al origen de los profesionales, tenemos que 26 son inmigrantes, un $14,6 \%$ del total y un 15,85\% de los médicos de familia. De estos el 52,7\% son mujeres. Provienen de: Argentina, Bolivia, Colombia, Cuba, Ecuador, Moldavia, República Dominicana, Rumanía y Venezuela. Agrupando los orígenes por zonas geográficas se observa que el $23,1 \%$ provienen de países del este europeo y que el 80,7\% son de origen latinoamericano.

En el análisis bivariante se encuentra que tener nacionalidad extranjera y contratos temporales están estadísticamente relacionados $(\mathrm{p}<0,00)$. También hay significación estadística para la edad según el origen, siendo los extranjeros más jóvenes con respecto a los autóctonos. 


\subsection{Análisis cualitativo}

Realicé entrevistas a 5 médicos extranjeros, 4 médicos autóctonos y 8 pacientes, tres de ellas grupales. A continuación, en la tabla 2, se especifican las características de cada informante.

Tabla 2. Codificación y características de los informantes, según perfiles

\begin{tabular}{|c|c|c|c|}
\hline Código & Sexo & Edad & Observaciones \\
\hline \multicolumn{4}{|l|}{ Médicos extranjeros } \\
\hline ME1 & Mujer & 35 & $\begin{array}{l}\text { Rumanía. Llegada en 2007. MIR España. Cl. } \\
\text { Habla catalán. }\end{array}$ \\
\hline ME2 & Mujer & 40 & Rumanía. Llegada en 2005. MIR España. Cl. \\
\hline ME3 & Mujer & 44 & Cuba. Llegada en 2009. Finalizando MIR. \\
\hline ME4 & Mujer & 46 & $\begin{array}{l}\text { Cuba. Llegada en 2007. Especialidad origen. } \\
\text { CE. }\end{array}$ \\
\hline ME5 & Mujer & 30 & $\begin{array}{l}\text { República Dominicana. Llegada en 2011. No } \\
\text { especialidad. Máster en España. CE. }\end{array}$ \\
\hline \multicolumn{4}{|l|}{ Médicos autóctonos } \\
\hline$M A 1$ & Mujer & 56 & $\begin{array}{l}\text { Especialidad convalidada (no MIR). } 32 \text { años EP. } \\
\mathrm{Cl} \text {. }\end{array}$ \\
\hline MA2 & Mujer & 34 & MIR. 2 años EP. Cl. \\
\hline$M A 3$ & Mujer & 41 & MIR. 12 años EP. Cl. \\
\hline MA4 & Hombre & 35 & Zaragoza. MIR. 7 años EP. Cl. \\
\hline \multicolumn{4}{|l|}{ Pacientes } \\
\hline$P_{1}$ & Mujer & 53 & $\begin{array}{l}\text { Ama de casa y trabajos esporádicos de } \\
\text { limpieza, educación básica. }\end{array}$ \\
\hline$P_{2}$ & Mujer & 49 & $\begin{array}{l}\text { Licenciada en Historia, profesora en una } \\
\text { escuela de arte. }\end{array}$ \\
\hline$P_{3}(a, b, c, d)$ & Hombres & $\begin{array}{l}38,45 \\
47,49\end{array}$ & $\begin{array}{l}\text { Entrevista grupal. Bomberos. Educación } \\
\text { secundaria y superior. }\end{array}$ \\
\hline$P_{4}(a, b, c)$ & Hombres & $\begin{array}{c}43,43 \\
54\end{array}$ & $\begin{array}{l}\text { Entrevista grupal. Bomberos. Educación } \\
\text { secundaria y superior. }\end{array}$ \\
\hline$P_{5}$ & Mujer & 71 & Ama de casa, educación básica. \\
\hline P6 & Mujer & 36 & Cuidadora profesional, educación secundaria. \\
\hline$P 7(a, b, c, d, e, f, g, h, i)$ & $\begin{array}{l}\text { Hombres } \\
\text { y mujeres }\end{array}$ & $\begin{array}{c}19,27, \\
22,23, \\
25,22, \\
56,50, \\
58\end{array}$ & $\begin{array}{l}\text { Entrevista grupal. Estudiantes con educación } \\
\text { secundaria y profesores de una escuela de arte. }\end{array}$ \\
\hline P8 & Hombre & 73 & Estudios básicos, jubilado, electricista. \\
\hline
\end{tabular}




\begin{tabular}{|c|c|c|c|}
\hline \multicolumn{4}{|l|}{ Expertos } \\
\hline Dirección ICS & Mujer & 35 & $\begin{array}{l}\text { Coordinadora unidad funcional de gestión } \\
\text { Montsià. }\end{array}$ \\
\hline Concejal Salud & Hombre & 37 & $\begin{array}{l}\text { 4. }{ }^{\circ} \text { teniente de alcalde; concejal de Deportes, } \\
\text { Salud y Medio Ambiente y Natural. } \\
\text { Ayuntamiento de Alcanar. }\end{array}$ \\
\hline$S_{1}(a, b)$ & $\begin{array}{l}\text { Hombre/ } \\
\text { mujer }\end{array}$ & $61 / 51$ & $\begin{array}{l}\text { Representantes territoriales del sindicato } \\
\text { Unión Ceneral de Trabajadores. }\end{array}$ \\
\hline S2 & Hombre & 64 & $\begin{array}{l}\text { Representante territorial del Sindicato Metges } \\
\text { de Catalunya. }\end{array}$ \\
\hline
\end{tabular}

*MIR: médico interno residente, vía de obtener la especialidad médica en España;

EP: experiencia profesional; CI: contrato indefinido; CE: contrato eventual.

Según los expertos entrevistados, las razones que generan la falta de facultativos son tres principalmente: la elevada tasa de jubilaciones, las condiciones laborales y los sueldos no acordes con la actividad realizada que fuerzan a itinerarios profesionales fuera del país. Los cambios culturales en las nuevas generaciones de médicos que valoran más los tiempos personales y la feminización de la profesión, generando vacantes laborales durante los períodos reproductivos, jugarían un papel menor en la causalidad.

En 5 anys 55.000 metges a España i en 10 anys se calcula 115.000 metges es jubilaran (Sia).

Els metges que acaben el MIR, són metges ben formats, però com els sous aquí són baixos i les condicions són dolentes, la gent té alternatives a altres països. (S1a)

Esta necesidad de facultativos hace que la Administración recurra a profesionales sin especialidad, por lo que existen dos bolsas de trabajo, una para médicos especialistas y otra para generalistas. Por otro lado, a los médicos extracomunitarios «se'ls ha de fer un laboral (contratos)» (Dirección ICS), así como tampoco se les pueden realizar contratos de interinaje, siendo laborales indefinidos. Actualmente, estando en posesión del título de especialista, el período de inestabilidad laboral es muy corto, menor a un año, y a los especialistas extranjeros recién acabados se les ofrecen contratos de un año para que puedan gestionar el permiso de trabajo. 
La formación vía MIR es la mejor considerada por sindicatos y Administración. Para aquellos recién llegados se reclama un período formativo para adaptarse al sistema, para lo que la dirección comentó que se encontraba en trámites de elaborar.

S'hauria de fer, tres mesos, com es feia a la mili, tres mesos d'adaptabilitat aquí, a tot, [...] es que... les costums són diferents, l'alimentació és diferent, tot es diferent, [...] tres mesets per adaptar-se a la situació del país, demostrat que tu estàs capacitat amb un tutor especialista (S2) Lo que estem muntant és un pla d'acollida [...] de formació que doni uns mínims garantits de certes patologies. [...] està fet per comarques, explica com funciona la comarca [...] on se deriva i tot això, i per circuits de com es funciona a cada lloc [...] uns mòduls diferents que ell tingui que fer abans de començar a treballar (Dirección ICS).

Otra de las cuestiones remarcadas ha sido la implicación en el territorio por parte de los profesionales como algo deseado e idealizado por la población.

Jo penso que la vinculació en el territori és vital, estic convençut que altres països hi han excellents metges i excellents professionals però implicar-se en un territori és vital, per a formar part d'aquell projecte i poder-lo tirar endavant (concejal Salud).

A continuación se describen los resultados de las entrevistas para cada uno de los perfiles.

\subsubsection{Médicos autóctonos}

Existe una desconfianza respecto a la formación recibida, la cual mejora si el MIR se ha realizado en España, así como un cuestionamiento a la imagen y al comportamiento, sobre todo entre el colectivo de latinoamericanos, que resultan ser los peor valorados.

Los que hacen la especialidad aquí cuando vienen a trabajar trabajan mejor, a mí me da esa sensación, los que vienen de fuera y les han homologado el título..., para el día a día todos se apañan, no sé, a mí me parece que falta un poco o de formación o de implicación. [...] Porque hay alguno de los que viene que..., para tratar un catarro todo el mundo 
sabe, pero un paciente diabético, un paciente cardiópata, un paciente con riesgo cardiovascular, algo hay que saber. Si no, no te pegas cuatro años de especialidad para tratar mocos (MA4).

La impressió general que dóna és que el nivell és sempre més baix, esta és la impressió, llavors que veus també que molts, no tots, molts compensen que el tracte al pacient és molt dolcet, molt [...] suposo que és com aquí que hi ha de tot. [...] pot ser més els de Sud-Amèrica, pot ser els d'aquí d'Europa, sent diferents no acaben de ser tant així (MA1).

Hi han companys que no guarden la compostura, de dir, van vestits de qualsevol manera (MAI).

Els que han fet la formació aquí segueixen la línia, però en quant a caràcter no els canvia (MA1).

Sí que és veritat que hi ha diferencia, per que els que s'han format aquí normalment són més resolutius, també saben pos, bàsicament los protocols, la forma d'actuació, saben com agrada a l'hospital que faigues les coses, allavontes això sí que se nota, però crec que més que s'hagin format o no s'hagin format és que estiguin acostumbrats treballa la, a la zona o no, com a coneixements crec que tenen més coneixement els que s'han format aquí (MA2).

No tenen la formació d'aquí, no es responsabilitzen del pacient. No són tant responsables, sobre tot els latinoamericans (MA3).

Por otro lado, también existe un cuestionamiento a su implicación y arraigo con el territorio, lo cual, según los informantes, generaría relaciones superficiales y la no resolución de las demandas de los pacientes.

Tinc la sensació que estan de passo, que no es volen quedar aquí i com més de passo estan menys relació estableixen, no ho viuen com nosaltres. La sensació no és bona (MA3).

Los pacients t'ho diuen: estos de fora, la negreta, lo negret, la peruana, no n'encerten ni un! [risas] i quan estan ells, entrar i sortir i tornen al dia següent (MA3).

[Hablando de un compañero extranjero que lleva tiempo trabajando en el mismo lugar]. És diferent, és una persona que ha decidit quedar-se, ho viu diferent, treballa diferent, la seva parella és d'aquí, s'ha comprat una casa aquí... (MA3). 
I no s'acaba tot en vingui al seu metge de capçalera, vingui al seu metge de capçalera, per que pa' n'això que fiquin un lletrero a fora la consulta i au! (MA2).

A pesar de todo, reconocen la precariedad laboral a la que están sujetos en muchas ocasiones y la falta de implicación por parte de la empresa en ofrecerles unas bases formativas del funcionamiento del sistema; todo ello contribuiría al clima de desconfianza.

Venen desconeixent el idioma, desconeixen el programa i se troben d'avui pa' demà a la consulta, sense que els hagin fet, que això no és culpa d'ells! Això és culpa de la direcció, sense haver fet la formació que tocava i això al final acaba repercutint en ells (MA2).

No se'ls forma per treballar a l'empresa. No pots amollar algú a la consulta sense saber ni el sistema [informático] (MA3).

Amb el que estudiem i el via crucis que passes com tenim unes condicions laborals tant dolentes (MA3).

És gent que s'adapten a tot, tot. Si se'ls expliqués bé pot ser s'adaptarien (MA3).

Refieren comentarios al respecto de la imagen del «buen profesional», ya que la falta de conocimientos puede suplirse con una mejora en el comportamiento y estableciendo buenas relaciones médico-paciente.

Pot ser un metge mediocre però si ets i fas el que s'espera, semblarà que ets molt més (MA1).

A veces más importante que la formación es el trato que tienes con la gente, al final es más importante expresar lo poco que sabes que si uno sabe mucho y no lo sabe expresar (MA4).

\subsubsection{Pacientes}

Por un lado, existe una confianza en cuanto a la validez de la formación de los médicos extranjeros, se da por supuesto que si ocupan una plaza en el sistema y se les contrata es porque cumplen con los requisitos, con lo que se hace a la Administración responsable de garantizarla. Aunque, por otro lado, se les cuestiona profesionalmente, existiendo unos prejuicios 
que posteriormente pueden desaparecer, en función de la relación que se establece.

Suposant que la formació és igual, no hi ha d'haver problema, la multiculturalitat està bé, depèn més de l'individuo professional ( $\left.\mathrm{P}_{3} \mathrm{~b}\right)$.

Si s'homologuen és perquè evidentment, els coneixement o la manera de treballar o de ensenyar deu ser la mateixa (P4b).

Pues no sé, da como cosa, igual son igual o más buenos, pero no me dan la misma confianza, es una cuestión de confianza (P5).

Ostres! A mi em diràs racista! Però les poques que he tingut han sigut amb sud-americans i la primera impressió... (P4a).

Si tenen lo coneixement que siguin d'on vulguen, mentres tinguen lo coneixement de curar que més dóna es suposa que la medicina és vocacional, que tens la empatia i vols ajudar a la gent (P7b).

Hi han molts prejudicis, depèn de quin país ve és diferent, per exemple ve un anglès i no hi ha cap problema, li serà molt més facil que un de Kènia o deee, jo que sé! estem parlant de sanitat que en teoria tots aprenen lo mateix $(\mathrm{P} 7 \mathrm{~h})$.

En general, las posibles discrepancias surgen de la situación del sistema, que produce cambios constantes de médicos en un mismo lugar de trabajo, lo que repercute en la población, que no tiene una figura profesional fija con la que establecer un vínculo, y, también, de lo que se espera del profesional en cuanto a la relación con el usuario, es decir, con el concepto del «buen médico».

Que hi hagin metges..., m'és igual que siguin estrangers, que siguen espanyols o catalans, lo que si que interessa és que sempre hi haigue lo mateix metge a cada consulta (P8).

Jo tinc dos xiquetes i un dia les vaig portar, va llaure una substitució d'un metge, metge de capçalera, diguem-se, i ho va fer un metge de fora, no sé si era de polonès o així i mirava tot lo rato en un llibre, i la visita em va agradar, lo vaig vore molt, molt..., preocupat per la meua nena i això sempre en los metges d'aquí no passa ( $\mathrm{P} 4 \mathrm{~b})$.

Jo penso que si són bons professionals me dóna igual d'on vinguin, si a mi em resolen el problema que tinc i són bons professionals i a més te- 
nen este plus de que són agradables i que prenen interès pos si, escolta, perfecte, a mi em sembla perfecte, no tinc cap problema en això, [...] o lo típic, que vas i estan davant de l'ordinador i ni t'hi miren [...] mira'm a la cara!, reconforta'm! (P2).

Per mi un bon metge és que sapiga escoltar (P6).

\subsubsection{Médicos extranjeros}

En esta muestra las razones para migrar son múltiples (estudios, investigación, amor, deseo de trabajar en un sistema sanitario más desarrollado) y las económicas solo salen a relucir, como factores coadyuvantes, en el discurso de las dos médicas rumanas, cosa que contrasta con el imaginario de médicos autóctonos y pacientes, que refieren que la principal causa por la que están aquí es para ganar dinero.

Se va el qué tiene la posibilidad de irse, es una decisión individual (ME4).

Cada uno toma sus decisiones que son para toda la vida. Yo estoy mejor que en Rumanía, pero hay que salir con ganas de salir. Me voy porque quiero, me voy porque lo deseo (ME2).

En cuanto a la formación, todas ellas relatan una formación similar a la española, a pesar de los matices diferenciales en cuanto a prácticas y contenidos. En el caso de Rumanía, la dificultad de acceso a la especialidad juega un papel primordial en la decisión de las médicas para realizarla en España.

La llegada al territorio es casual pero mediatizada por una red de relaciones previas de familiares o amigos que ya se encontraban en la zona.

Hay que diferenciar entre la homologación de la Licenciatura de Medicina, que fue bastante rápida y sencilla burocráticamente en todos los casos, y la homologación del título de especialista, el cual es un proceso largo que llegó a los ocho años de duración en el caso de ME4, con elevada carga tanto burocrática como económica. Además, durante ese tiempo no pueden inscribirse en la bolsa de trabajo de especialistas del ICS, si no en una bolsa de médicos generales, a los cuales solo se les ofrecen contractos de tipo temporal, cosa que genera mayor precariedad laboral, inestabilidad e incertidumbre respecto al futuro. Una vez la homologación 
de la especialidad se hace efectiva, se accede a la bolsa de especialistas en la que ya se puede optar a contratos de tipo indefinido. Para los médicos que realizan la formación de la especialidad en territorio español, vía MIR, el acceso a esta bolsa es directo.

Ninguna de ellas ha sentido discriminación por parte de compañeros o de pacientes.

¡Vaya!, de sentirme a menos porque no era de aquí, no. [...] la relación con los compañeros y los pacientes, todo bien (ME4).

No somos del terreno pero yo no veo ninguna diferencia (ME2).

Els pacients si ho fas bé et veuen igual (ME1).

Nunca he resentido nada de nadie, ni que me traten con racismo (ME5).

Al inicio, tuvieron ciertas dificultades de adaptación, en cuanto al programa informático, los circuitos, la lengua, la cultura, etc., pero consideran que la atención al paciente es similar.

¿Dificultades? Con el sistema informático, pero el trabajo es el mismo, a la gente se la tiene que atender igual (ME5).

Quan marxes del teu país has de fer canvis si o si, una altra cultura, un altre sistema...si tu has pres aquesta decisió t'has d'adaptar. No és facil, no és el teu país, no és el teu idioma, no tens la família...estàs sol (ME1).

Se encuentran satisfechas con su decisión y con su vida aquí. El mito del retorno es variable, para algunas está muy presente, mientras que otras ni se lo plantean.

Penso en tornar per la família..., ara que tinc una filla vull algo més de tranquillitat (ME1).

Intención de volver siempre hay [...]. En el momento que yo vea que no puedo trabajar de lo mío me regreso (ME5).

No me planteo regresar, mi marido, mi vida, ya está aquí (ME3).

Ya no tengo nada allá, mis hijos son de aquí, mi marido, de aquí, no me veo volviendo allí (ME4). 


\section{Discusión}

El porcentaje de médicos extranjeros especialistas en medicina de familia en les Terres de l'Ebre es de 15,85\%, siendo el perfil mayoritario mujeres jóvenes latinoamericanas con contratos eventuales. Esta proporción es suficientemente representativa y, según las previsiones, tenderá a aumentar en los próximos años. Estos facultativos provienen principalmente de países de Latinoamérica, reproduciendo lazos coloniales similares a los producidos en el Reino Unido con los países de la Commonwealth (Raghuram, 2008). Así pues, como nos dice Sassen (2013: 186), «el país exportador de mano de obra se ve colocado en una posición subordinada», por lo que se puede considerar una geopolítica de la migración.

La introducción de facultativos en Cataluña sigue los patrones de otros modelos como el del Reino Unido, que tiene una larga trayectoria en acoger médicos extranjeros en su sistema sanitario, presentando, históricamente, desde su creación, un elevado porcentaje de ellos. Ha existido una diferenciación entre los médicos provenientes de países de la Commonwealth y los originarios de países de la Unión Europea. Sobre los primeros existía una cultura de sospecha, ya que se les creía menos competentes y cualificados, cosa que generó una serie de medidas políticas y legales para asegurar las equivalencias en competencias y habilidades. La tendencia en el Reino Unido en la última década ha sido la de deshacerse de la dependencia de los médicos extranjeros, sobre todo de los no comunitarios, y equiparar la producción interna de médicos a las necesidades del sistema. Existe una incerteza en los procesos de integración de los profesionales sanitarios en el Reino Unido, con una tendencia a la segregación horizontal y vertical, a los puestos de trabajo de menor prestigio y con menos oportunidades de progresión profesional, tienen poca información y un reconocimiento limitado de su experiencia, así como la necesidad inmediata de ocupación por el requisito del visado, lo cual les hace susceptibles a aceptar cualquier trabajo, el cual, posteriormente, les es difícil cambiar. Se encuentran, pues, en una situación de segregación y vulnerabilidad, en la que ocupan nichos laborales por debajo de su calificación y en peores condiciones laborales que sus homólogos nacionales, en una situación de discriminación institucional (Raghuram, 2008; 
Meardi, 2011). Así, según Gray (1981), aunque existe un reconocimiento de que sin los profesionales extranjeros no se sostendría el Servicio Nacional de Salud británico, existe la consideración entre ellos de que sus propios colegas les otorgan el estatus de segunda clase y que son tratados como médicos subalternos en el hospital; la falta de conocimientos de la lengua y la cultura inglesas se califica de desventaja.

Según el modelo que planteó Ravestein (1885), la migración de los facultativos a nuestro país se explica por un efecto push (centrífugo o de expulsión) protagonizado por una situación laboral precaria y poco atractiva, con sueldos bajos y elevada presión asistencial, así como una pérdida del prestigio social ligado a la profesión médica. Y, por otro lado, por un efecto pull (centrípeto o de atracción) que generaría espacios laborales vacantes y una necesidad de cubrirlos con mano de obra cualificada. Para ello, se acude, principalmente, a los países periféricos con los que existen relaciones históricas y en los que las diferencias económicas y de recursos materiales hacen de la migración una opción atractiva. Este efecto convierte a nuestro país en destino migratorio de personal facultativo en los próximos años. Al mismo tiempo, esta situación produce secundariamente una disminución de profesionales en los países de origen, generando, a su vez, un déficit de facultativos que va a agravar la situación de sus sistemas sanitarios. Este modelo de pull y push viene a ejemplificar la teoría del carrusel médico de Eastwood.

Así pues, se pueden considerar dos grandes grupos entre los médicos extranjeros: en cuanto al origen (el grupo de latinoamericanos y los provenientes de los países del este europeo) y en cuanto a la formación (aquellos que hicieron la migración posteriormente a la formación especializada y aquellos que migran para realizarla en España). Estas dos diferencias marcan las relaciones que se establecen con el grupo de iguales, sobre todo, y también con los pacientes, ya que son dos cuestiones que median en la mayor o menor aceptación. Ello crea, simbólicamente, en el imaginario colectivo, una especie de jerarquización que categoriza a los facultativos extranjeros en un gradiente de calidad.

Por un lado, los formados vía MIR en España se encontrarían por encima de aquellos que obtuvieron la especialidad en otros países y, a su 
vez, por encima de los que no tienen especialidad médica. Este último grupo concentraría la mayor precariedad e inestabilidad laboral, ya que, como he comentado anteriormente, no se les puede realizar contratos indefinidos. Los resultados de este estudio siguen la tendencia descubierta por Freire y Masanet (2013), que detectaron dos perfiles en las trayectorias de los médicos latinoamericanos en Cataluña. Por un lado, aquellos profesionales que deciden realizar la formación especializada, vía MIR, en nuestro país. Esta opción ofrece un mejor modo de incorporación al mercado laboral, pudiendo realizar una red de contactos y una socialización en el entorno profesional y personal, además de que la experiencia y la red que se adquieren forma parte de su «capital cultural y no necesitan ser reproducidas o convalidadas en la sociedad de destino» (Freire y Masanet, 2013:3), lo cual permite una mayor igualdad de oportunidades con los médicos autóctonos. Por otro lado, están aquellos que realizan la migración para la incorporación, directamente, al mercado laboral; estos son los que encuentran mayores dificultades o barreras para su proceso de integración profesional, presentan mayor precariedad laboral, y para los cuales los procesos de homologación de títulos resultan lentos y con niveles de exigencia elevados, incidiendo directamente y de forma negativa en sus trayectorias profesionales, colocándoles en un contexto de perjuicio y desigualdad, así como en una situación de mayor vulnerabilidad e incertidumbre laboral. Los mismos autores comentan que existen prejuicios respecto a la formación recibida en origen, la cual se identifica como de baja calidad, así como «desconfianza profesional e infravaloración de sus competencias formativas y técnicas por parte de los compañeros autóctonos y en menor medida por el resto de personal sanitario y los pacientes, sobre todo al inicio de su actividad laboral» (ibid.: 5).

Por otro lado, considerando el origen, el escalón superior sería para los europeos occidentales, seguidos por los provenientes de los países del este europeo; más abajo tendríamos a los latinoamericanos, y, por último, estarían los originarios de países islámicos. Muy posiblemente, este hecho tenga relación con las características fenotípicas, así como con el nivel de capital nacional, del que habla Hage (2000; 2003), que tienen los diferentes colectivos. De esta forma, a mayor similitud con la sociedad catalana, mayor aceptación por parte de esta. 
Las relaciones establecidas entre las diferentes categorías, tanto las formativas como las fenotípicas, no ejercerían cuotas de poder unas sobre otras al estilo foucaultinano, más bien serían ventajas simbólicas que incidirían en mejoras en las relaciones y en la obtención de una mejor posición laboral y social. Se trataría pues, de etiquetas sociales (Pujadas, 1993) que comportarían ventajas o inconvenientes en los procesos de integración dentro del sistema sanitario y de la sociedad de acogida.

Pienso que esta categorización nace de varios factores: los prejuicios y estereotipos para con otras culturas, las cuestiones legales y burocráticas alrededor de las homologaciones y tipos de contrataciones, la situación del sistema sanitario que genera espacios de continua rotación de profesionales, cosa que dificulta tanto su implicación en el territorio como la posibilidad de establecer vínculos estables con los usuarios, y cuestiones de imagen corporal y fenotípica. Todo ello conformaría la creación del capital nacional (Bourdieu, 1979) incidiendo en el grado de inclusión o exclusión individual del colectivo de médicos extranjeros.

A propósito del arraigo y a pesar de que la idea de retorno de las médicas extranjeras entrevistadas no está presente, existe por parte del resto de perfiles entrevistados una insistencia en su falta de implicación en el territorio. Creo que tiene que ver con la imagen prejuzgada que se tiene de este colectivo, de su etiquetaje social, y de la situación laboral en la que se encuentra una parte del mismo, que presenta una elevada movilidad en la región, impidiendo la creación de alianzas con los pacientes a los que atienden, cosa que proporciona una imagen de superficialidad y de no vinculación. Esa implicación deseada viene dada por la estabilidad en un mismo lugar de trabajo y la creación de relaciones médico-pacientes continuadas en el tiempo que resulten satisfactorias para los usuarios.

En ese fenómeno también se pone en juego el concepto de «buen médico», que tiene una carga simbólica importante y que, a su vez, presenta matices según se describa desde el punto de vista profesional o del usuario. Es decir, que aparecen cuestiones de «eficacia simbólica» que producen acuerdos o desacuerdos con el proceder de los médicos extranjeros en la consulta en función de las imágenes conceptuales esperadas, tanto por el grupo de iguales como por parte de los pacientes. Así, tal como nos dice Lévi-Strauss: 
La carga simbólica de tales actos les permite construir un lenguaje: en realidad, el médico dialoga con su paciente no mediante la palabra, sino mediante operaciones concretas, verdaderos ritos que atraviesan la pantalla de la consciencia sin encontrar obstáculo, para aportar directamente su mensaje al inconsciente (2011: 223).

Pero esto será más o menos posible en función de la proximidad de un marco simbólico compartido por profesionales y enfermos que permite la construcción de un lenguaje común. A mayor distancia, mayor probabilidad de rechazo y de conflictividad.

A propósito del «buen médico», Camps (2007) publicó un artículo online titulado «La excelencia en las profesiones sanitarias», en el cual la autora reflexiona sobre las características que debería tener un buen profesional. Así pues, argumenta que la acepción habitual de la excelencia profesional está relacionada con la competencia científica y técnica, con la posesión de unos conocimientos y un conjunto de habilidades específicas. Un buen profesional sería, ante todo, un experto, pero como he podido observar en este trabajo, la población demanda otras virtudes al médico para considerarlo un buen profesional. Más allá del reduccionismo y la simplificación característica de un mundo que valora los comportamientos de las personas por los resultados más que por los principios a los que deberían atenerse y servir, la idónea formación científica y técnica es el primer deber moral en cualquier profesión, pero no el único. La excelencia técnica debe ir acompañada del compromiso ético y tiene que ver con una amplitud de miras del profesional hacia la ética, con la sensibilidad humana hacia las personas. De esta forma, Camps enumera una serie de virtudes a las cuales todo profesional que busque la excelencia debería tender: benevolencia, respeto, cuidado, sinceridad, amabilidad, justicia, compasión, integridad, olvido de uno mismo y prudencia. Todas ellas «no se consiguen a través de clases teóricas sobre la ética profesional. Se aprenden en el ejercicio diario, en la práctica que lleva a tener que resolver problemas y conflictos cotidianamente» (Camps, 2007: 8).

Por lo tanto, aunque, en general, las relaciones entre los tres actores principales considerados en esta investigación son satisfactorias, existen imágenes preconcebidas por parte de médicos y usuarios respecto al co- 
lectivo de facultativos extranjeros, que pueden ser corroboradas o desmentidas de forma particular según la personalidad y la profesionalidad de cada uno. «Nuestra simpatía deriva de nuestro conocimiento del grado en el que se ha ganado sus puntos de vista. [...] si deseamos ser capaces de juzgar competentemente, como por supuesto debemos, necesitamos llegar a ser también capaces de ver competentemente» (Geertz, 1996: 92).

El panorama laboral actual y futuro expuesto por los informantes resulta un tanto desolador. La falta de previsión con respecto a las necesidades de médicos nos posiciona en una situación difícil para la cobertura de todas las plazas vacantes. Por esta razón la entrada de médicos extranjeros al sistema público catalán se prevé que vaya en aumento en los próximos años, modificando la apariencia de las consultas e introduciendo la multiculturalidad, no como objeto de atención, sino como proveedora del servicio.

Creo que las diferentes características del sistema sanitario actual, como son la feminización; el envejecimiento de la población médica; la precarización laboral de los profesionales debido a masificación de las consultas, aumento de las exigencias por parte de gestores y usuarios, horarios de trabajo poco flexibles con abundantes horas extra, etc.; así como la precarización del sistema para la población, con listas de espera crecientes, pérdida del médico de referencia por la constante rotación de profesionales, la atención por parte de médicos cada vez menos motivados, y la entrada de facultativos extranjeros, producen una situación crítica del sistema para la cual es preciso realizar cambios organizativos y estructurales que se adapten a los cambios sociales y que permitan recuperar nuevamente la homeostasis y la confianza, tanto de la población como de los propios profesionales.

Tenemos un buen sistema sanitario, dicen, incluso, que es uno de los mejores del mundo, ya que es universal, gratuito, con acceso a la tecnificación y a recursos materiales y humanos, que nos permite disfrutar de una elevada esperanza de vida. A pesar de ello, creo que nos encontramos en un momento delicado, en el que peligra su supervivencia. La reforma de la AP en los años siguientes a la transición democrática estaba bien intencionada y, en global, ha aportado beneficios a la población, pero la 
situación de crisis económica; la excesiva burocratización; la rigidez tanto organizativa como de actuación profesional; un modelo centrado en el hospital con mayor aportación económica en este, en detrimento de la AP, entre otros factores, han llevado al sistema a una situación límite con un descontento generalizado tanto por parte de los profesionales, que sufren un agotamiento psicológico y una falta de motivación, como por parte de la población, que es, en última instancia, quien sufre las consecuencias de la situación. Resulta necesario y urgente un cambio estructural, pero también de paradigma, para que todos: sistema, profesionales y usuarios, podamos adaptarnos al contexto presente y, para ello, creo que son necesarias la voluntad política de hacerlo, un cambio en el modelo sanitario centrándolo en la AP y una reestructuración económica que dote del presupuesto requerido a la AP para que pueda hacer frente a los retos que se le presentan.

En todo este complejo situacional, la presencia de la diversidad cultural entre el colectivo médico no llega más que, por un lado, a poner de manifiesto las deficiencias del sistema, y, por otro lado, a introducir nuevos elementos a tener en cuenta, ya que, como hemos visto, los prejuicios y el etiquetaje social están bien presentes en las relaciones establecidas entre los actores, así como la preocupación por los niveles formativos y la consiguiente disminución de la calidad asistencial.

Para finalizar, existe un contexto laboral que genera una atracción para este tipo de migración y, en consecuencia, una adaptación al fenómeno por parte de todos los actores implicados. Así, como dice Bauman:

El desconocido es la incógnita variable de todas las ecuaciones, una incógnita que debe calcularse antes de decidir cómo se debe proceder y actuar; aunque no sean objeto de ataques directos, ni exista una hostilidad manifiesta hacia ellos, la presencia de forasteros en nuestro campo de acción sigue produciendo incomodidad, puesto que complican enormemente la labor de predecir los efectos de nuestras acciones y sus posibilidades de éxito o fracaso (2006: 27-28). 


\section{Bibliografía}

Bauman, Zygmunt (2006). Confianza Y Temor En La Ciudad. Vivir Con Extrangeros. Barcelona: Arcadia.

Bourdieu, P. (1979). «Los tres estados del capital cultural». Sociológica, (5), 11-17. Recuperado de: <http://sociologiac.net/biblio/Bourdieu-LosTresEstadosdelCapitalCultural.pdf $>$.

Bourdieu, P. (2002). Campo de poder, campo intelectual. Madrid: Montressor. CAMPs, Victoria (2007). «La excelencia en las profesiones sanitarias». Humanitas Humanidades Médicas, 21 (tema del mes online). Recuperado de: $<$ http://www.ehu.eus/SEMDE/archivos_pdf/archivos_pdf/Victoria Camps La excelencia en las profesiones sanitarias-1.pdf>.

Col-legi Oficial de Metges de Tarragona (2016). Galens, 193, 1-36. Recuperado de: <http://www.comt.org/index.php/actualitat-i-publicacions/ publicacions/revista-galens/1749-edicio-galens-193>.

Directiva 93/16/CEE, del Consejo. Consejo de la Unión Europea, de 5 de abril de 1993.

Eastwood, J. B.; Conroy, R. E.; Naicker, S.; West, P. A.; Tutt, R. C. y PlanGE-Rhule, J. (2005). «Loss of Health Professionals from Sub-Saharan Africa: The Pivotal Role of the UK». The Lancet, 365 (9474), 1893-1900.

Freire, A. y Masanet, E. (2013). «Médicos latinoamericanos en Cataluña: procesos de integración y desarrollo profesional». REMHU: Revista Interdisciplinar Da Mobilidade Humana, 21 (41), 225-240. Disponible en: <http://doi.org/10.1590/S1980-85852013000200012>.

GARZÓN, Luis (1996). «La epistemología de la investigación sobre migraciones cualificadas en la Europa del Sur». Recuperado de: <http:// www.academia.edu/713580/La_epistemología_de_la_investigación_ sobre_migraciones_cualificadas_en_la_Europa_del_sur $>$.

GeERTZ, Clifford (1996). Los usos de la diversidad. Madrid: Espasa Libros. Gray, C. (1981). «Second class status for immigrant doctors in the UK?» Canadian Medical Association Journal, 124 (9), 1198, 1200, 1202. Recuperado de: <http://ovidsp.ovid.com/ovidweb.cgi?T=JS\&PAGE=referen$\mathrm{ce} \& \mathrm{D}=$ med $2 \& N E W S=\mathrm{N} \& A N=7237341>$.

HAGE, G. (2000). White Nation: fantasies of White supremacy in a multicultural society. New York: Routledge. 
Hage, G. (2003). Against Paranoid Nationalism: searching for hope in a shrinking society. Annandale, NSW: Pluto Press.

Herrera, Encarna (1994). «Reflexiones en torno al concepto de integración en la sociología de la inmigración». Papers. Revista de Sociología, 43, 7176.

LÉvi-Strauss, Claude (s. f.). Antropología Estructural (6. ${ }^{a}$ ed.). Barcelona: Espasa Libros. Barcelona.

Martínez Guevara, Carlos; Guiu Barragán, Elisa e Ibáñez Nolla, Jordi (2008). Pasado, presente y futuro de la interculturalidad médica en los servicios de urgencias. Emergencias, 20 (agosto), 131-134.

Martiniello, Marco (2003). La Europa de las migraciones. Por una política proactiva de la inmigración. Barcelona: Edicions Bellaterra.

MeArdi, Guglielmo (2011). International migration of Health Workers: can Spain follow the British steps? En Industrial Relations in Europe Conference 2011: Beyond the Crisis: Industrial Relations and Sustainable Growth, Barcelona, España, 1-2 de septiembre de 2011. Recuperado de: <http://wrap. warwick.ac.uk/47015/>.

OMC (2016). Estudio sobre la situación laboral de los médicos de España.

Pujadas, Joan Josep (1993). Etnicidad. Identidad cultural de los pueblos. Madrid: EUDEMA.

Raghuram, Parvati (2008). "Thinking UK's Medical Labour Market Transnationally». En J. Connell (ed.). The International Migration of Health Workers (pp. 182-198). (s. 1.): Routledge. Routledge Research in Population and Migration.

Ravenstein, E. G. (1885). «The Laws of Migration». Journal of the Statistical Society of London, 48 (2), 167. Recuperado de: <http://www.jstor.org/ stable/2979181?origin=crossref $>$.

REDACIÓn MÉdiCA (2016). «La nota de corte de medicina para el curso 20162017 sube un 3\%». Recuperado de: <http://www.redaccionmedica. $\mathrm{com} /$ secciones/formacion/la-nota-de-corte-de-medicina-para-elcurso-2016-2017-sube-un-3--5280>.

SASSEN, Saskia (2013). Inmigrantes y ciudadanos. De las migraciones masivas a la Europa Fortaleza. Madrid: Siglo XXI. 
